\title{
Social Networking Technology, Social Network Composition, and Reductions in Substance Use Among Homeless Adolescents
}

\author{
Eric Rice • Norweeta G. Milburn • William Monro
}

Published online: 31 December 2010

(C) The Author(s) 2010. This article is published with open access at Springerlink.com

\begin{abstract}
Peer-based prevention programs for homeless youth are complicated by the potential for reinforcing highrisk behaviors among participants. The goal of this study is to understand how homeless youth could be linked to positive peers in prevention programming by understanding where in social and physical space positive peers for homeless youth are located, how these ties are associated with substance use, and the role of social networking technologies (e.g., internet and cell phones) in this process. Personal social network data were collected from 136 homeless adolescents in Los Angeles, CA. Respondents reported on composition of their social networks with respect to: home-based peers and parents (accessed via social networking technology; e.g., the internet, cell phone, texting), homeless peers and agency staff (accessed face-toface) and whether or not network members were substanceusing or non-substance-using. Associations between respondent's lifetime cocaine, heroin, and methamphetamine use and recent (previous 30 days) alcohol and marijuana use were assessed by the number of nonsubstance-using versus substance-using ties in multivariate linear regression models. $43 \%$ of adolescents reported a non-substance-using home-based tie. More of these ties were associated with less recent alcohol use. $62 \%$ of
\end{abstract}

E. Rice $(\bowtie) \cdot$ W. Monro

School of Social Work, University of Southern California,

Montgomery Ross Fisher Bldg, 669 West 34th St,

Los Angeles, CA 90089-0411, USA

e-mail: ericr@usc.edu

\section{N. G. Milburn}

Department of Psychiatry and Biobehavioral Sciences, Center for Community Health, Semel Institute for Neuroscience and Human Behavior, University of California-Los Angeles, 10920 Wilshire Blvd, Suite 350,

Los Angeles, CA 90024, USA adolescents reported a substance-using homeless tie. More of these ties were associated with more recent marijuana use as well as more lifetime heroin and methamphetamine use. For homeless youth, who are physically disconnected from positive peers, social networking technologies can be used to facilitate the sorts of positive social ties that effective peer-based prevention programs require.

Keywords Homeless adolescents · Alcohol · Marijuana . Social network $\cdot$ Social networking technology

\section{Introduction}

Peer-based prevention models are difficult to design for high-risk adolescents such as homeless youth, because models that only incorporate high-risk youth have the potential to enhance negative outcomes through what has come to be known as "deviancy training." (Dishion and Dodge 2005; Dodge et al. 2006; Gifford-Smith et al. 2005; Lavallee et al. 2005). The histories of abuse and neglect at the hands of adults which are so common among homeless youth (Greene et al. 1999; Herman et al. 1997; Kipke et al. 1997a; Whitbeck and Hoyt 1999) make peer-based prevention programming an appealing approach for this population. The prevalence of high-risk behaviors among these youth, however, raises serious concerns about the potential for deviancy training. Effective peer-based models for adolescents require a blending of low-risk/pro-social peers and high-risk youth in prevention groups (Dodge et al. 2006). If effective peer-based models for homeless youth are to be created, prevention science must grapple with where in social and physical space low-risk/prosocial peers can be found and how homeless youth can access these peers. 
There are an estimated 1.6 million runaway and homeless adolescents in the United States each year (Ringwalt et al. 1998). Research has consistently documented levels of cocaine, heroin, methamphetamine, alcohol and marijuana use and abuse among these adolescents that far exceed that of housed adolescents (Booth and Zhang 1997; Fors and Rojek 1991; Greene et al. 1997; Kipke et al. 1997a; Milburn et al. 2006; Rice et al. 2005; Ringwalt et al. 1998; Unger et al. 1997; Yates et al. 1988). Engagement with other substance using homeless adolescents has consistently been tied to the substance use of homeless adolescents (Hagan and McCarthy 1992; Kipke et al., 1997b; McMorris et al. 2002; Slesnick and Meade 2001; Tyler 2008; Whitbeck and Hoyt 1999; Whitbeck et al. 2000). Not all homeless adolescents, however, are substance users (Booth and Zhang 1997; Greene et al. 1997; Kipke et al., 1997a; Unger et al. 1997; Milburn et al. 2006; Rice et al. 2005; Yates et al. 1988) and having more non-using homeless peers should be associated with decreased levels of substance use.

Recent research has revealed that most homeless adolescents continue to maintain relationships with homebased peers (Johnson et al. 2005; Rice 2010, Rice et al. 2007). Johnson and his colleagues (2005) found that over $80 \%$ of their sample reported having at least one current network relationship formed prior to their life on the streets. Likewise, Rice and his colleagues found that $73 \%$ of their sample of newly homeless adolescents (homeless for less than 6 months) claimed that most or all of their friends attended school regularly, $24 \%$ claimed most or all of their friends had jobs, and $50 \%$ claimed most or all of their friends got along with their families (Rice et al. 2007). Moreover, presence of these prosocial peers reduced hard drug use (cocaine, methamphetamine and heroin) over time (Rice et al. 2007).

Whitbeck (2009) have suggested that there may be two distinct trajectories for homeless youths' social network engagement. Some adolescents enter homelessness and rapidly become embedded in networks filled with other risk-taking youth, while other youth may never make a complete transition to street life. These latter youth gravitate toward home and family over time (Whitbeck 2009). These home-based relationships may promote healthy behaviors. Alternatively, maintaining such ties may reflect "healthy" network choices on the part of more resilient youth who are able to maintain their distance from street life by maintaining connections to home.

Social networking technology (i.e. internet, cell phones, texting) is key to accessing healthier social networks that are home-based (Rice 2010). Homeless adolescents are often physically disconnected from their home-based networks, (Brooks et al. 2004; Whitbeck \& Hoyt 1999). Social networking technology is ubiquitous in lives of adolescents
(Boyd 2008; Gross et al. 2002) and homeless youth, though they are resource poor, utilize these relatively cheap technologies to maintain their relationships with homebased peers (Rice 2010; Rice et al. 2010). Fifty-three percent of homeless youth have at least one peer relationship which they maintain through these technologies (Rice 2010 ) and nearly $85 \%$ of homeless youth get online at least once per week (Rice et al. 2010). Thus, we expect that contact with more home-based peers who are substanceusing ought to be associated with more substance use, while more contacts to non-substance-using home-based peers ought to be associated with less substance use.

Beyond peers, family members are also critical network ties for some homeless youth (Johnson et al. 2005; Milburn et al. 2005). Recent work has demonstrated that while interactions with family may be problematic, families can have a positive role in the life of homeless adolescents (Milburn et al. 2005, 2009). Nearly one-third of homeless adolescents include parents as key social ties in their networks (Johnson et al. 2005) and increased contact with parents increased the likelihood that newly homeless adolescents exited homelessness and remained stably housed over time (Milburn et al. 2009). Early childhood exposure to alcohol and drug use and abuse in families of origin, however, normalizes high levels of substance use (MacLean et al. 2007; Whitbeck and Hoyt 1999; Whitbeck et al. 2000). Continued contact with parents who themselves are substance users ought to be associated with more substance use, while continued contact with non-using parents ought to be associated with less substance use.

Staff at social service agencies can also be important ties for homeless youth. Social service agencies are locations where homeless adolescents can interact with agency staff who can play key roles as supportive adult mentors (De Winter and Noom 2000; Karabanow and Rains 1997; Lindsey et al. 2000; McGarth \& Pistrang 2007; Thompson et al. 2006). There is a large body of research that has consistently demonstrated the healthy impact of having a positive adult in the life of high-risk adolescents (Beam et al. 2002; Grossman and Rhodes 2002; Hamilton and Darling 1996; Hirsch et al. 2002; Rhodes et al. 2000). Connections to agency staff at social service organizations ought to be associated with less substance use.

This study is an examination of the composition of the social networks of homeless adolescents and how variations in type of ties are associated with lifetime cocaine, heroin, and methamphetamine use as well as recent alcohol and marijuana use. We pay particular attention to how accessing home-based network ties via social networking technology may be associated with substance use. We collected detailed personal social network data, often called "egocentric" network data in social network research (McCarty et al. 2007; Wasserman and Faust 1994). Using these data 
we are able to simultaneously model the associations of individual adolescent's substance using behavior with the presence of substance-using versus non-substance-using: homeless, home-based, parent, and social service agency staff ties in their networks.

\section{Methods}

\section{Sample}

A convenience sample of 136 adolescents was recruited between June 19 and August 21, 2008 in Los Angeles, California at one drop-in agency serving homeless adolescents. All clients, age 13 to 24 , receiving services at the agency during the period of study were eligible to participate. In 2008, the agency saw 1,860 individual adolescents who visited a total of 30,575 times. Adolescents were asked if they would like to participate in the survey at the same time they signed up to receive services at the agency (e.g. a shower, clothing, case management); only 14 youth $(9.3 \%)$ declined to participate. A consistent set of two research staff members was responsible for all recruitment to prevent adolescents completing the survey multiple times. Signed voluntary informed consent was obtained from each adolescent, with the caveats that physical or sexual abuse, suicidal and homicidal feelings would be reported. Informed consent was obtained from adolescents 18 years old and older. For minors, loco parentis consent was obtained from an agency staff member, who was not part of the research team and informed assent was obtained from participants. Interviewers received approximately $40 \mathrm{~h}$ of training, including lectures, role-playing, mock surveys, ethics training, and emergency procedures.

\section{Procedures}

All surveys were conducted in a private space at the agency. The survey consisted of two distinct parts. In total, both parts of the interview lasted approximately $60 \mathrm{~min}$. All participants received a \$20 gift card as compensation for their time. Survey items and procedures were approved by the university's Institutional Review Board.

Part one was a computer administered self-interview where adolescents answered survey items pertaining to demographics, sex and drug risk taking, living situation, service utilization, and mental health. To alleviate issues of low literacy, all youth were offered the opportunity to have the interview read aloud to them while they entered answers on a laptop computer. One youth opted for this procedure.

Part two was a face-to-face network mapping interview conducted by a trained interviewer that collects personal network data from each participant. Personal network data are also called "ego-centric" network data in social network analysis (McCarty et al. 2007; Wasserman and Faust 1994). Reducing participant burden in the collection of personal social network data is of great concern to social network research (McCarty et al. 2007). Our data collection technique yielded standard personal network data, while providing a visual stimulus that reduced participant burden and enhanced the adolescent's ability to focus on providing a large quantity of social network data.

First, interviewers explained that they were interested in collecting information about the adolescent's social network in the previous month. The following text was read aloud: "Think about the last month. Now I am going to draw a map of your network. We are interested in the people you interact with. We're interested in the people you talk to, people you hang out/kick it/chill with, people you have sex with or hook up with, people you party with or drink or use drugs with?"

Next, the interviewer wrote the adolescent's name in the center of a large piece of white paper. The interviewer then read a series of prompts to the participant to elicit network nominations; after each prompt interviewers recorded nominations on the paper in a large arc around the adolescent's name. The following set of prompts were always read: "friends; family; people you hang out with/ chill with/kick it with/have conversations with; people you party with - use drugs or alcohol; boyfriend/girlfriend; people you are having sex with; baby mama/baby daddy; case worker or agency staff; people from school; people from work; old friends from home; people you talk to (on the phone, by email); people from where you are staying (squatting with); people you see at this agency; other people you know in Hollywood."

After adolescents finished nominating persons, a series of questions about attributes of each nomination were then asked. For example to determine if the nominated person was home-based, interviewers asked, "Which of these people did you know from home, before you became homeless?" The interviewers were trained to ask the adolescents about each attribute of every nomination on the page and record all responses. Attributes recorded included: "parent or guardian," "case worker or agency staff," "homeless," someone who "drink alcohol or uses marijuana," someone from "home, before you became homeless" and "how long a respondent had known this person." Youth were then asked to provide information on which nominated persons likely "knew" what other nominated persons on a pair by pair basis. Nominationlevel responses for every participant were then entered into a data base by a research assistant and checked for quality assurance by another research assistant after the interview. 


\section{Measures}

All demographic variables were coded from self-reported data. Recent and lifetime alcohol and marijuana use items were drawn from the CDC Youth Risk Behavior Study. Lifetime substance use was assessed from answers to three items: "During your life, on how many days have you: (1) used any form of cocaine, including powder, crack, or freebase?; (2) used heroin (also called smack, junk, or China White)?; (3) used methamphetamines (also called speed, crystal, crank, or ice)?" Responses were coded on a 6-point scale: "(1) 0 times, (2) 1 or 2 times, (3) 3 to 9 times, (4) 10 to 19 times, (5) 20 to 39 times, (6) 40 or more times." Recent alcohol use was coded using the item "During the past 30 days, on how many days did you have at least one drink of alcohol?" Responses ranged from: "(1) 0 days, (2) 1 or 2 days, (3) 3 to 5 days, (4) 6 to 9 days, (5) 10 to 19 days, (6) 20 to 29 days, (7) All 30 days." Recent marijuana use was coded using the item "During the past 30 days, how many times did you use marijuana?" Responses ranged from "(1) 0 times, (2) 1 or 2 times, (3) 3 to 9 times, (4) 10 to 19 times, (5) 20 to 39 times, (6) 40 or more times."

Social network variables were coded independently for each respondent based on that respondent's "ego-centric" network data. Two types of network ties were recorded, face-to-face ties: "who do you spend time with face to face, hanging out, chilling with, or have conversations with" and electronic ties: "who do you only communicate with by phone, email, or texting in the past month." Network size was coded based on the total number of nominees in the network. Network density was coded based on the number of actual ties reported by the respondent divided by the number of ties possible for that respondent's network based on the size of the network (Wasserman \& Faust 1994).

Seven variables that measure network influences were coded by summing the total number of particular ties nominated in a given youth's personal social network. For case workers, the total number of case workers nominated was totaled (in only one instance was a case worker labeled as using alcohol or drugs; removing that tie from the analysis did not affect the results). For parents, the total number of substance-using ties and substance-non using ties were tallied separately. For peers, the total number of home-based non-substance-using ties, home-based substance-using ties, homeless non-substance-using ties, and homeless substance-using ties were tallied separately.

\section{Analysis}

Pearson's $r$ correlations among substance use and independent network variables were run. Because personal social network data assesses the social network of each individual respondent independently of one another, it can be transformed into variables that can be incorporated into standard linear modeling techniques. For this study, five separate multivariate ordinary least squares (OLS) regression models were run. Outcomes were recent alcohol and marijuana use and lifetime cocaine, heroin, and methamphetamine use. Because of the modest sample size, not all possible social network variables were included in the final models. After adding social network variables one at a time, only network variables that were significantly associated with at least one outcome were retained in the final model. The final model included the number of non-substance-using home-based ties, the number of substance-using homeless ties, network size and density. Demographic controls that have been associated with substance using behaviors among homeless adolescents in previous studies were also included (i.e., age, race, gender, years homeless) (Booth and Zhang 1997; Fors and Rojek 1991; Greene et al. 1997; Kipke et al. 1997b; Milburn et al. 2006; Rice et al. 2005; Unger et al. 1997; Yates et al. 1988).

\section{Results}

Most adolescents were male, African American, and between the age of 18 and 22 years old (youngest was 16, only 6 were minors). Frequency distributions for substance use are illustrative: $9 \%$ reported lifetime heroin use, $34 \%$ reported lifetime methamphetamine use, 30\% reported lifetime cocaine use, $69 \%$ reported recent alcohol use, and $58 \%$ reported recent marijuana use.

Their networks were quite diverse. The average network size was greater than 13 with a standard deviation of 8 . Network density was relatively low, with most adolescents reporting networks comprised of only $20 \%$ of possible ties. Table 1 presents the mean and standard deviations of the network composition variables. $43 \%$ of adolescents reported a tie to a non-substance-using home-based peer, while only $31 \%$ reported a tie to a substance-using home-based peer. $38 \%$ reported a tie to a non-substance-using homeless peer, while $62 \%$ reported a tie to a substance-using homeless peer. $32 \%$ reported a non-substance-using parent, while only $18 \%$ included a substance-using parent in their network, and $44 \%$ of adolescents included a case worker.

Relationships with homeless peers were of a shorter duration than relationships with home-based peers. Youth were asked to specify for how long they had known each tie nominated. For homeless ties, $42 \%$ of relationships were less than 6 months old, while only $20 \%$ were greater than 2 years in duration. For home-based ties, however, only $2 \%$ of relationships were less than 6 months old, whereas $89 \%$ of home-based relationships were reported to be greater than 2 years in duration. 
Table 1 Individual characteristics and social network properties, homeless youth, Los Angeles, CA, $2008(n=136)$

\begin{tabular}{|c|c|c|}
\hline Individual characteristics & Mean & Std Dev \\
\hline \multirow[t]{2}{*}{ Years homeless } & 4.51 & 4.39 \\
\hline & $\mathrm{N}$ & $\%$ \\
\hline Male & 81 & 60.45 \\
\hline \multicolumn{3}{|l|}{ Race } \\
\hline Native American & 7 & 5.15 \\
\hline Asian & 1 & 0.74 \\
\hline African American & 48 & 35.29 \\
\hline Native Hawaiian or Pacific Islander & 2 & 1.47 \\
\hline White & 27 & 19.85 \\
\hline Latino & 20 & 14.71 \\
\hline Mixed race/ethnicity & 31 & 22.79 \\
\hline \multicolumn{3}{|l|}{ Age } \\
\hline $16-17$ & 6 & 4.44 \\
\hline $18-19$ & 35 & 25.93 \\
\hline $20-21$ & 42 & 31.12 \\
\hline $22-23$ & 36 & 26.67 \\
\hline $24-25$ & 14 & 10.37 \\
\hline \multicolumn{3}{|l|}{ Social network properties } \\
\hline Size & 13.46 & 8.09 \\
\hline Density & 0.22 & 0.21 \\
\hline \multicolumn{3}{|l|}{ Number of ties in network } \\
\hline Non-using home-based & 1.15 & 2.01 \\
\hline Using home-based & 0.63 & 1.28 \\
\hline Non-using homeless & 0.98 & 1.71 \\
\hline Using homeless & 2.44 & 3.45 \\
\hline Non-using parent & 0.36 & 0.57 \\
\hline Using parent & 0.24 & 0.56 \\
\hline Case worker & 1.38 & 2.61 \\
\hline \multicolumn{3}{|l|}{ Substance use } \\
\hline \multicolumn{3}{|l|}{ Lifetime substance use } \\
\hline Heroin & 1.25 & 0.94 \\
\hline Methamphetamine & 2.20 & 1.93 \\
\hline Cocaine or crack & 1.70 & 1.34 \\
\hline \multicolumn{3}{|l|}{ Recent substance use } \\
\hline Alcohol & 2.62 & 1.69 \\
\hline Marijuana & 2.90 & 1.99 \\
\hline
\end{tabular}

Several bivariate correlations among network characteristics and substance use emerged as significant in Table 2. Lifetime heroin use was associated with more substanceusing homeless ties. Lifetime methamphetamine use was associated with more substance-using homeless ties and substance-using parent ties. Lifetime cocaine use was associated with higher network density. Lower levels recent alcohol use (past 30 days) was associated with more nonsubstance-using home-based peers. Higher levels of recent alcohol use were correlated with more ties to substance- using homeless peers and substance-using parents. Recent marijuana use was correlated with more substance-using homeless peers and negatively correlated with more case worker ties.

The results of the multivariate OLS regressions are presented in Table 3. Lifetime heroin use was significantly associated with more substance-using homeless ties, higher network density, and older age. A positive trend $(p<.10)$ was observed for lifetime heroin use and increased network size. Likewise, lifetime methamphetamine use was associated with more substance-using homeless ties and White race/ ethnicity (relative to non-white youth). White youth also reported higher levels of lifetime cocaine use; however, no social network variables were significant for this substance.

More substance-using home-based peers were associated with less recent alcohol use (past 30 days), while alcohol use was associated with more ties to substance-using homeless peers. There was a positive trend $(p<.10)$ toward an association between years homeless and recent alcohol use. Frequency of recent marijuana use was associated with more ties to substance-using homeless peers and associated with smaller overall network size. Older age was associated with less recent marijuana use. There was a positive trend $(p<.10)$ toward an association between years homeless and recent marijuana use.

\section{Discussion}

There are several important findings to emerge from this study. First, social networking technology (i.e. internet and cell phones) was a critical resource connecting homeless adolescents to their non-substance-using home-based ties. Approximately $50 \%$ of adolescents nominated a parent in the social network and nearly $75 \%$ nominated a homebased tie with whom they kept in touch via social networking technology. Positive influences were a subset of these overall connections, with nearly one third of adolescents nominating a non-substance-using parent and nearly $40 \%$ nominating a non-substance-using home-based peer. These results buttress recent findings and suggest that despite the physical dislocation from home (and in most cases, school), homeless adolescents continue to remain connected to positive home-based social ties (Johnson et al. 2005; Milburn et al. 2006; Rice et al. 2007).

Although prosocial contacts exist in the face-to-face networks of homeless adolescents, these ties were not significantly associated with substance use. Almost half of the homeless adolescents in the sample nominated a case worker or other social service agency staff member in their networks and these ties were associated with less substance-use in bivariate analyses. These face-to-face ties, however, were not significantly associated with substance 
Table 2 Correlations among substance use and social network properties, homeless youth in Los Angeles, CA, 2008 $(n=136)$

${ }^{*} p<.05, * * p<.01, * * * p<.001$

\begin{tabular}{|c|c|c|c|c|c|}
\hline & \multicolumn{3}{|l|}{ Lifetime } & \multicolumn{2}{|l|}{ Recent } \\
\hline & Heroin & Meth & Cocaine & Alcohol & Marijuana \\
\hline Non-using, home-based & -0.10 & -0.10 & -0.15 & $-0.23 * *$ & -0.15 \\
\hline Using, home-based & -0.01 & 0.03 & 0.00 & 0.10 & -0.06 \\
\hline Non-using, homeless & -0.14 & -0.16 & -0.16 & -0.13 & -0.04 \\
\hline Using, homeless & $0.27 * *$ & $0.38 * * *$ & 0.12 & $0.33 * * *$ & $0.19 *$ \\
\hline Non-using, parent & -0.07 & -0.01 & -0.08 & -0.15 & -0.09 \\
\hline Using, parent & 0.14 & $0.19 *$ & 0.15 & $0.21 *$ & 0.03 \\
\hline Case worker & -0.13 & -0.13 & -0.10 & -0.15 & $-0.24 * *$ \\
\hline Size & -0.01 & 0.14 & -0.07 & 0.14 & -0.21 \\
\hline Density & 0.15 & -0.06 & $0.17 *$ & -0.12 & 0.17 \\
\hline
\end{tabular}

use once other network ties were entered into the multivariate models and case worker ties were dropped from the final multivariate models. In addition, ties to nonsubstance-using homeless peers exist within the face-toface networks of homeless adolescents. These ties, however, were not significantly associated with substance use in bivariate or multi-variate analyses.

Most importantly, these data reveal a tension between the healthy associations with ties to non-substance-using homebased peers (online and over the phone) and the unhealthy associations of ties to substance-using homeless peers (face-toface). More connections to non-substance-using home-based peers was associated with less recent alcohol use. More ties to substance-using homeless peers was associated with higher levels of heroin, methamphetamine, alcohol, and marijuana use, which is in keeping with most work on homeless adolescent substance use (Hagan and McCarthy 1992; Kipke et al. 1997a; McMorris et al. 2002; Rice et al. 2005; Slesnick \& Meade 2001; Tyler 2008; Whitbeck and Hoyt 1999).
Home-based ties were more enduring over time than street-based ties; nearly $90 \%$ of these home-based ties have a duration of 2 years or more, while only $20 \%$ of streetbased relationships have existed for 2 or more years. These findings expand recent work (Rice et al. 2005, 2007, 2010) that has examined the influence of "prosocial" peers in the lives of homeless adolescents by locating these prosocial peers in social space and physical space; namely, at home and accessed via phone and the internet, not in face-to-face homeless networks.

Taken together, these results lend weight to Whitbeck and colleagues' (2009) suggestion that there may be two distinct trajectories of network involvement for homeless youth. One group is made up predominantly of youth who become heavily involved in a succession of relatively shortlived relationships with other homeless youth and their lifestyles of risk-taking and substance use. Simultaneously, a second group of homeless youth may exist who do not become fully embedded in these networks, remaining

Table 3 OLS regression models of lifetime and recent substance use by social network and individual characteristics, homeless youth, Los Angeles, CA, $2008(n=136)$

\begin{tabular}{|c|c|c|c|c|c|c|c|c|c|c|}
\hline & \multicolumn{6}{|c|}{ Lifetime substance use } & \multicolumn{4}{|c|}{ Recent substance use } \\
\hline & \multicolumn{2}{|c|}{ Heroin b Std Err } & \multicolumn{2}{|c|}{ Meth b Std Err } & \multicolumn{2}{|c|}{ Cocaine b Std Err } & \multicolumn{2}{|c|}{ Alcohol b Std Err } & \multicolumn{2}{|c|}{ Marijuana b Std Err } \\
\hline \multicolumn{11}{|l|}{ Number of ties in network } \\
\hline Non-using home-based & 0.03 & 0.04 & -0.06 & 0.11 & -0.04 & 0.07 & -0.29 & $0.10 * *$ & 0.00 & 0.11 \\
\hline Using homeless & 0.08 & $0.02 * * *$ & 0.18 & $0.06 * *$ & 0.03 & 0.04 & 0.13 & $0.05 * *$ & 0.19 & $0.06 * *$ \\
\hline Size & 0.02 & 0.01 & -0.01 & 0.03 & 0.03 & 0.02 & 0.01 & 0.03 & -0.08 & $0.03 *$ \\
\hline Density & 2.39 & $0.49 * * *$ & -0.33 & 1.42 & 2.45 & 0.91 & -0.20 & 1.25 & 0.38 & 1.42 \\
\hline Male & 0.00 & 0.13 & -0.19 & 0.37 & -0.20 & 0.24 & 0.37 & 0.32 & 0.10 & 0.37 \\
\hline White & 0.46 & 0.16 & 1.23 & $0.46 * *$ & 1.27 & $0.30 * * *$ & 0.11 & 0.41 & 0.45 & 0.46 \\
\hline Age & 0.00 & $0.03 * *$ & 0.09 & 0.09 & -0.02 & 0.06 & -0.12 & 0.08 & -0.21 & $0.09 *$ \\
\hline Years homeless & 0.01 & 0.02 & 0.01 & 0.04 & -0.01 & 0.03 & 0.07 & 0.04 & 0.08 & 0.04 \\
\hline Intercept & 0.17 & 0.64 & 0.04 & 1.84 & 1.04 & 1.18 & 4.57 & 1.60 & 7.27 & 1.82 \\
\hline R-square & 0.38 & & 0.22 & & 0.27 & & 0.20 & & 0.22 & \\
\hline
\end{tabular}

$* p<.05, * * p<.01, * * * p<.001$ 
attached to home-based peers and family over time, and maintaining these relationships for years at a time. These home-based relationships may promote healthy behaviors via prosocial modeling or homeless youth may use these home-based peers as their primary reference group when they are evaluating their own behaviors. Alternatively, successfully maintaining these prosocial home-based relationships may be a reflection of the greater emotional and social health of this group of more resilient youth. These data suggest that regardless of the causal logic, cell phones and the internet are the technologies employed by these youth to maintain these ties. As we discuss below, social networking technology may greatly facilitate prevention efforts for these youth.

There are a few important limitations to the current study. First, these data are not causal. The associations could be due to selection (i.e., adolescents who are substance users form networks with other substance users). Alternatively, it was possible that the homeless adolescents who themselves were using less substances attributed their healthier behaviors to their highly regarded home-based peers (about whose behaviors they are likely making some assumptions). It is important to bear in mind that perceptions of peers' antisocial behaviors influence youths' antisocial behaviors (Berndt 1979; Collins et al. 1987; Graham et al. 1991; Marks et al. 1992; Sussman et al. 1988). Social networking technology has changed the ways that adolescents monitor one another's intimate behaviors at a distance (Subrahmanyam and Greenfield 2008). Posting pictures from parties where adolescent substance use occurs is an all-too-common phenomenon on Facebook and MySpace. Homeless youth likely have a pretty good idea what their home-based peers are doing. Second, these data are imprecise with respect to the use of social networking technology. Unfortunately, these data to not differentiate among ties maintained through email, social-networking websites such as MySpace or Facebook, a cell phone, texting, or even a standard phone accessed at a social service agency. Third, these data are drawn from a convenience sample and are subject to the biases of such a sampling strategy. Perhaps more prosocial adolescents, with more prosocial peers volunteered for the survey. The lack of residential stability or institutional attachments inherent to homelessness make residential or school-based sampling strategies impossible, and often convenience sampling at agencies serving adolescents is the only viable way to collect data from this population. Fourth, these data were drawn from only one drop-in service agency. Despite the heterogeneity of this sample with respect to age, race, and gender/ethnicity, one must be cautious in generalizing the results beyond service-seeking youth in Los Angeles (who are disproportionately African American and male).
This study opens important directions for future research. Given the importance of social networking technology as a tool for accessing prosocial network ties, a great deal more information about just how homeless adolescents utilize social networking technology is needed. It is easy to assume that resource-poor populations such as homeless adolescents lack access to cell phones and the internet. Most of these adolescents had at least one peer with whom such means were the primary mode of communication. In general, more work is needed on how resource-poor communities are accessing new technologies, and homeless adolescents would be an ideal starting point. A probability based sampling strategy would greatly enhance the generalizability of future data.

These findings have important implications for prevention science's efforts to create effective peer-based models for homeless youth (and perhaps other marginalized and dislocated youth). Prevention models that only utilize faceto-face ties to street-based youth would appear unwise. When too many high-risk youth are brought together, "deviancy training" or the reinforcement of high-risk behaviors is likely (Dishion and Dodge 2005; Dodge et al. 2006; Gifford-Smith et al. 2005; Lavallee et al. 2005), and these data suggest that such processes could occur in peer-based programs that only included homeless youth. These data suggest that incorporating home-based nonsubstance-using peer relationships could be an effective component of peer-based models for the prevention of substance using behaviors. These youth are not on the streets and prevention programming must take advantage of social networking technologies as a platform for new modalities in prevention. We do not intend to suggest that cell phones and the internet are some panacea for prevention. Prevention science needs to consider not only by what means peer-based models connect people (i.e., social networking websites or small face-to-face groups) but to whom people are being connected. What these data make clear is that for homeless youth, who are physically disconnected from positive peers, these new technologies could be used to facilitate the sorts of social ties that effective peer-based prevention programs seek to create.

Open Access This article is distributed under the terms of the Creative Commons Attribution Noncommercial License which permits any noncommercial use, distribution, and reproduction in any medium, provided the original author(s) and source are credited.

\section{References}

Beam, M. R., Chen, C., \& Greenburg, E. (2002). The nature of adolescents' relationships with their "very important" nonparental adults. American Journal of Community Psychology, 30, 305327. doi:10.1023/A:1014641213440. 
Berndt, T. J. (1979). Development changes in conformity to peers and parents. Developmental Psychology, 15, 608-616. doi:10.1037// 0012-1649.15.6.608.

Booth, R. E., \& Zhang, Y. (1997). Conduct disorder and HIV risk behaviors among runaway and homeless adolescents. Drug and Alcohol Dependency, 48, 69-76. doi:10.1016/S0376-8716(97)00113-0.

Boyd, D. (2008). Why youth "heart" social network sites: The role of networked publics in teenage social life, youth, identity, and digital media. In D. Buckingham (Ed.), Youth, identity, and digital media (pp. 119-142). Cambridge, MA: MIT Press.

Brooks, R. A., Milburn, N. G., Rotheram-Borus, M., \& Witkin, A. (2004). The system-of-care for homeless youth: Perceptions of service providers. Evaluation Program \& Planning, 27, 443451. doi:10.1016/j.evalprogplan.2004.07.007.

Collins, L. M., Sussman, S., Rauch, J. M., Dent, C. W., \& Clyde, W. (1987). Psychosocial predictors of young adolescent cigarette smoking: A sixteen-month, three-wave longitudinal study. Journal of Applied Social Psychology, 17, 554-573. doi:10.1111/ j.1559-1816.1987.tb00330.x.

De Winter, M., \& Noom, M. (2000). Someone who treats you as an ordinary human being: Homeless youth examine the quality of professional care. British Journal of Social Work, 33, 325-337. doi:10.1093/bjsw/33.3.325.

Dishion, T. J., \& Dodge, K. A. (2005). Peer contagion in interventions for children and adolescents: Moving towards an understanding of the ecology and dynamics of change. Journal of Abnormal Child Psychology, 33, 395-400. doi:10.1007/s10802-005-3579-z.

Dodge, K. A., Dishion, T. J., \& Lansford, J. E. (2006). Deviant peer influences in programs for youth: Problems and solutions. New York: Guilford Press.

Fors, S. W., \& Rojek, D. G. (1991). A comparison of drug involvement between runaways and school youths. Journal of Drug Education, 21, 13-25.

Gifford-Smith, M., Dodge, K. A., Dishion, T. J., \& McCord, J. (2005). Peer influence in children and adolescents: Crossing the bridge from developmental to intervention science. Journal of Abnormal Child Psychology, 33, 255-265. doi:10.1007/s10802-0053563-7.

Graham, J. W., Marks, G., \& Hansen, W. B. (1991). Social influence processes affecting adolescents' substance use. Journal of Applied Social Psychology, 76, 291-298.

Greene, J. M., Ennett, S. T., \& Ringwalt, C. L. (1997). Substance use among runaway and homeless youth in three national samples. American Journal of Public Health, 87, 229-235.

Greene, J., Ennett, S., \& Ringwalt, C. (1999). Prevalence and correlates of survival sex among runaway and homeless youth. American Journal of Public Health, 89, 1406-9.

Gross, E. F., Juvonen, J., \& Gable, S. L. (2002). Internet use and wellbeing in adolescence. Journal on Social Issue, 58, 75-90. doi:10.1111/1540-4560.00249.

Grossman, J. B., \& Rhodes, J. E. (2002). The test of time: Predictors and effects of duration in youth mentoring relationships. American Journal of Community Psychology, 30, 199-219. doi:10.1023/A:1014680827552.

Hagan, J., \& McCarthy, B. (1992). Street life and delinquency. British Journal of Sociology, 43, 533-561.

Hamilton, S. F., \& Darling, N. (1996). Mentors in adolescents' lives. In K. Hurrelman \& S. F. Hamilton (Eds.), Social problems and social contexts in adolescents (pp. 199-215). Hawthorne: Aldine de Gruyter.

Herman, D., Susser, E., Struening, E., \& Link, B. (1997). Adverse childhood experiences: Are they risk factors for adult homelessness? American Journal of Public Health, 87, 249-55. doi:10.2105/AJPH.87.2.249.

Hirsch, B. J., Mickus, M., \& Boerger, R. (2002). Ties to influential adults among black and white adolescents: Culture, social class, and family networks. American Journal of Community Psychology, 20, 289-303. doi:0.1023/A:1014689129369.

Johnson, K. D., Whitbeck, L. B., \& Hoyt, D. R. (2005). Predictors of social network composition among homeless and runaway adolescents. Journal of Adolescence, 28, 231-248. doi:10.1016/ j.adolescence.2005.02.005.

Karabanow, J. M., \& Rains, P. (1997). Structure versus caring: Discrepant perspectives in a shelter for street kids. Child Youth Service Review, 19, 301-322. doi:10.1016/S0190-7409(97) 00019-4.

Kipke, M. D., Montgomery, S. B., Simon, T. R., \& Inverson, E. F. (1997). "Substance abuse" disorders among runaway and homeless youth. Substance Use \& Misuse, 32, 969-986. doi:10.3109/10826089709055866.

Kipke, M. D., Simon, T. R., Montgomery, S. B., Unger, J. B., \& Iversen, E. F. (1997). Homeless youth and their exposure to and involvement in violence while living on the streets. Journal of Adolescent Health, 20, 360-367. doi:10.1016/S1054-139X(97) 00037-2.

Lavallee, K. L., Bierman, K. L., Nix, R. L., \& the Conduct Problems Prevention Research Group. (2005). The impact of first-grade "friendship group" experiences on child social outcomes in the Fast Track program. Journal of Abnormal Child Psychology, 33, 307-324. doi:10.1007/s10802-005-3567-3.

Lindsey, E. W., Kurtz, P. D., Jarvis, S., Williams, N. R., \& Nackerud, L. (2000). How runaway and homeless youth navigate troubled waters: Personal strengths and resources. Child and Adolescent Social Work Journal, 17, 115-140. doi:10.1023/ A:1007558323191.

MacLean, M. G., Embry, L. E., \& Cauce, A. M. (2007). Homeless adolescents' paths to separation from family: Comparison of family characteristics, psychological adjustment and victimization. Journal of Community Psychology, 27, 179-187. doi:10.1002/(SICI)1520-6629(199903)27:2.

Marks, G., Graham, J. W., \& Hanson, W. B. (1992). Social projection and social conformity in adolescent alcohol use: A longitudinal analysis. Personality and Social Psychology Bulletin, 18, 96101. doi: $10.1177 / 014616729218101$.

McCarty, C., Killworth, P. D., \& Rennell, J. (2007). Impact of methods for reducing respondent burden on personal network structural measures. Social Networks, 29, 300-315. doi:10.1016/ j.socnet.2006.12.005.

McGarth, L., \& Pistrang, N. (2007). Policemen or friend? Dilemmas in working with homeless young people in the United Kingdom. Journal of Social Issues, 63, 589-606. doi:10.1111/j.15404560.2007.00525.x.

McMorris, B., Tyler, K. A., Whitbeck, L. B., \& Hoyt, D. R. (2002). Familial and on the street risk factors associated with alcohol use among homeless and runaway adolescents. Journal of Studies on Alcohol, 63, 34-43.

Milburn, N. G., Rotheram-Borus, M., Batterham, P., Brumback, B., Rosenthal, D., \& Mallet, S. (2005). Predictors of close family relationships over 1 year among homeless young people. Journal of Adolescence, 28, 263-275. doi:10.1016/j.adolescence.2005. 02.006 .

Milburn, N. G., Rotheram-Borus, M., Rice, E., Mallet, S., \& Rosenthal, D. (2006). Cross-national variations in behavioral profiles among homeless youth. American Journal of Community Psychology, 37, 63-76. doi:10.1007/s10464-005-9005-4.

Milburn, N. G., Rice, E., Rotheram-Borus, M. J., Mallett, S., Rosenthal, D., Batterham, P., et al. (2009). Adolescents exiting homelessness over 2 years: The risk amplification and abatement model. Journal of Research on Adolescence, 19, 762-785. doi:10.1111/j.1532-7795.2009.00610.x.

Rhodes, J. E., Grossman, J. B., \& Resch, N. L. (2000). Agents of change: Pathways through which mentoring relationships influ- 
ence adolescents' academic adjustments. Child Development, 71, 585-604. doi:10.1111/1467-8624.00256.

Rice, E. (2010). The positive role of social networks and social networking technology in the condom using behaviors among youth. Public Health Reports, 125, 588-595. PMCID: PMC2882610.

Rice, E., Milburn, N. G., Rotheram-Borus, M., Mallet, S., \& Rosenthal, D. (2005). The effects of peer-group network properties on drug use among homeless youth. American Behavioral Scientist, 48, 1101-1123. doi:10.1177/0002764204274194.

Rice, E., Milburn, N. G., \& Rotheram-Borus, M. (2007). Pro-social and problematic social network influences on HIV/AIDS risk behaviors among newly homeless youth in Los Angeles. AIDS Care, 19, 697-704. doi:10.1080/09540120601087038.

Rice, E., Monro, W., Barman-Adhikari, A., \& Young, S. D. (2010). Internet use, social networking, and HIV/AIDS risk for homeless adolescents. Journal of Adolescent Health. doi:10.1016/j. jadohealth.2010.04.016

Ringwalt, C. L., Greene, J. M., Robertson, M., \& McPheeters, M. (1998). The prevalence of homelessness among adolescents in the United States. American Journal of Public Health, 88, 1325-1329.

Slesnick, N., \& Meade, M. (2001). System youth: A subgroup of substance-abusing homeless adolescents. Journal of Substance Abuse, 13, 367-384. doi:10.1016/S0899-3289(01)00082-7.

Subrahmanyam, K., \& Greenfield, P. (2008). Online communication and adolescent relationships. The Future of Children, 18, 119-46. doi:10.1353/foc. 0.0006 .

Sussman, S., Dent, C. W., Mestel-Rauch, J., \& Johnson, C. A. (1988). Adolescent nonsmokers, triers, and regular smokers' estimates of cigarette smoking prevalence: When do overestimations occur and by whom? Journal of Applied Social Psychology, 18, 537551. doi:10.1111/j.1559-1816.1988.tb00035.x.

Thompson, S. J., McManus, H., Lantry, J., Windsor, L. C., \& Flynn, P. (2006). Insights from the street: Perceptions of services and providers by homeless young adults. Evaluation Program \& Planning, 29, 1-10. doi:10.1016/j.evalprogplan.2005.09.001.

Tyler, K. A. (2008). Social network characteristics and risky sexual and drug related behaviors among homeless young adults. Social Science Research, 37, 673-685. doi:10.1016/j.ssresearch.2007.09.004.

Unger, J. B., Kipke, M. D., Simon, T. R., Montogomery, S. B., \& Johnson, C. J. (1997). Homeless youths and young adults in Los Angeles: Prevalence of mental health problems and the relationship between mental health and substance abuse disorders. American Journal of Community Psychology, 25, 371-394. doi:10.1023/A:1024680727864.

Wasserman, S., \& Faust, K. (1994). Social network analysis: Methods and applications. Cambridge, MA: Cambridge University Press.

Whitbeck, L. B. (2009). Mental health and emerging adulthood among homeless youth. New York: Psychology Press, Taylor \& Francis Group.

Whitbeck, L. B., \& Hoyt, D. R. (1999). Nowhere to grow: Homeless and runaway adolescents and their families. Hawthrone: Aldine De Gruyyer.

Whitbeck, L. B., Hoyt, D. R., \& Bao, W. N. (2000). Depressive symptoms and co-occurring depressive symptoms, substance abuse, and conduct problems among runaway and homeless adolescents. Child Development, 71, 721-732. doi:10.1111/1467-8624.00181.

Yates, G. L., MacKenzie, R., Pennbridge, J., \& Cohen, E. (1988). A risk profile comparison of runway and non-runaway youth. American Journal of Public Health, 78, 820-821. 